\title{
Region-specific genetic alterations in the aging hippocampus: implications for cognitive aging
}

\section{Corinna Burger*}

Department of Neurology, Medical Sciences Center, University of Wisconsin, Madison, USA

\section{Edited by:}

Thomas C. Foster, University of Florida, USA

\section{Reviewed by:}

Thomas C. Foster, University of Florida, USA

Brandi Ormerod, University of Florida, USA

\section{*Correspondence:}

Corinna Burger, Department of Neurology, Medical Sciences Center, University of Wisconsin, 1300 University Avenue Madison, WI 53706, USA. e-mail:burger@neurology.wisc.edu
Aging is associated with cognitive decline in both humans and animals and of all brain regions, the hippocampus appears to be particularly vulnerable to senescence. Age-related spatial learning deficits result from alterations in hippocampal connectivity and plasticity. These changes are differentially expressed in each of the hippocampal fields known as cornu ammonis 1 (CA1), cornu ammonis 3 (CA3), and the dentate gyrus. Each sub-region displays varying degrees of susceptibility to aging. For example, the CA1 region is particularly susceptible in Alzheimer's disease while the CA3 region shows vulnerability to stress and glucocorticoids. Further, in animals, aging is the main factor associated with the decline in adult neurogenesis in the dentate gyrus. This review discusses the relationship between region-specific hippocampal connectivity, morphology, and gene expression alterations and the cognitive deficits associated with senescence. In particular, data are reviewed that illustrate how the molecular changes observed in the CA1, CA3, and dentate regions are associated with age-related learning deficits. This topic is of importance because increased understanding of how gene expression patterns reflect individual differences in cognitive performance is critical to the process of identifying new and clinically useful biomarkers for cognitive aging.

Keywords: aging, hippocampus, microarray, neurogenesis, cognitive impairment, selective vulnerability, spatial memory

\section{INTRODUCTION}

The three main fields of the hippocampal region, CA1, CA3, and the dentate gyrus, possess distinctive anatomical, molecular and biophysical properties. Anatomical differences include cell type, size and projections (Swanson et al., 1987; Witter and Amaral, 2004; Amaral and Lavenex, 2007). First, the dentate gyrus consists of three layers: a granule cell layer, a molecular layer, and a polymorphic layer. Granule cells represent the major cell type in the dentate, and have the ability to proliferate all throughout life. The dentate receives inputs from the entorhinal cortex via the perforant pathway. Its major extrinsic projection is to field CA3 via granule cell mossy fibers. On the other hand, CA1-CA3 sub-regions are divided into four layers. The pyramidal cell layer, composed of a thick layer of pyramidal cell bodies, the stratum oriens, stratum lucidum, and stratum radiatum. Pyramidal cells are the major projection cells in areas CA1 and CA3. CA3 field is composed of large size pyramidal cells, whereas CA1 pyramidal neurons are relatively small. Field CA3 receives inputs from the dentate via mossy fibers, whereas CA1 does not. Moreover, CA3 is characterized by a complex set of projections within this region to the hilar region in the dentate, recurrent synapses within CA3, in addition to commissural projections to the contralateral subfields. The major extrinsic projection from $\mathrm{CA} 3$ is to $\mathrm{CA} 1$ via the Schaffer collateral fibers. Lastly, CA1 projects to the entorhinal area, thereby closing the entorhinal-dentate-CA3-CA1 circuit. Pyramidal neurons of CA1 also project to the subiculum. All these projections are modulated by excitatory and inhibitory interneurons located within each subfield. These unique anatomical and connectivity patterns that characterize each hippocampal field result in region-specific electrophysiological signatures. An example that illustrates this point is the differential expression of long-term potentiation (LTP) in the distinct hippocampal fields by disrupting genes that are normally expressed in all regions of the hippocampus, but selectively affect sub-region-specific synaptic plasticity (Schurmans et al., 1997; Chen et al., 2009). Similarly, aging affects connectivity in a region-specific manner with accompanying electrophysiological changes. These subfieldspecific connectivity alterations will be discussed in Section "AgeRelated Morphological and Plasticity Changes are Region-Specific and Correlate with Cognitive Impairment".

Molecular differences between the three hippocampal fields consist of differential gene and protein expression. Namely, different anatomical fields of the hippocampus have been shown to have distinct transcription and protein expression patterns (Datson et al., 2001; Zhao et al., 2001; Bonaventure et al., 2002; Gozal et al. 2002; Lein et al., 2004; Torres-Munoz et al., 2004; Greene et al., 2009). These anatomical, connectivity and molecular properties that characterize each region are altered in aging. This is not surprising as aging is frequently viewed as an inevitable or pathological process that alters brain structure and function. However, these age-related changes are characteristically different and occur to differing degrees in each field. So, while not intuitive, it may also be argued that these distinctive properties themselves confer a differential vulnerability to the effects of aging on each hippocampal field. Thus, this region-specific vulnerability may have genetic underpinnings. The genetic changes will be discussed in Section "Sub-regional Differences in Gene Expression Correlate with Cognitive Aging". 
Functional changes in the hippocampus have been implicated in the memory impairments associated with aging. These changes include a loss of synapses associated with synaptic plasticity (i.e., perforated synapses) in region CA1 of cognitive-impaired animals (Nicholson et al., 2004) and a loss of perforant path input to the dentate gyrus (Geinisman, 1979; Rogalski et al., 2009). This leads to several key questions. Do the functional changes and memory impairments show a similar regional association and vulnerability? Are these functional changes and memory impairments related to the age-associated alterations in anatomical, molecular, and biophysical properties? If so, how? Historically, neuronal cell loss was identified as one of the morphological hallmarks of hippocampal aging (Ball, 1977; Brizzee and Ordy, 1979). However, this generalized neuronal loss theory was disproved in the wake of the development of unbiased stereological methods (West et al., 1991; Geinisman et al., 1996; Mayhew and Gundersen, 1996). Instead, it has been demonstrated that morphological characteristics of hippocampal aging include changes in spine density and changes in rates of adult neurogenesis. Again, these particular changes occur selectively in specific fields of the hippocampus (Curcio and Hinds, 1983; Markham et al., 2005). Consequently, it appears that normal age-related memory deficits can result from functional changes that occur in the absence of major structural alterations. One mechanism by which this could occur is by a change in the expression of one or more genes. Altered gene expression could result in altered ion channel expression and/or dendritic spine morphology, ultimately affecting synaptic plasticity and behavior. In this regard, there is evidence that a number of genes important for learning in young animals show differential expression levels in the hippocampus of aged animals (Thibault and Landfield, 1996; Colombo et al., 1997; Lanahan et al., 1997; Colombo and Gallagher, 1998; Adams et al., 2001; Nicolle et al., 2001; Stephan et al., 2002; Hemby et al., 2003; Brightwell et al., 2004). In some cases, the expression changes occur in a regional-specific manner (Smith et al., 2000; Stephan et al., 2002; Jackson et al., 2009). Further, region-specific changes with aging diseases have been reported. These reports suggest that the CA1 region is more susceptible to amyloid plaque deposits and ischemia relative to CA3(Gozal et al., 2002; West et al., 2004; Zarow et al., 2005; Wu et al., 2008). This increased susceptibility appears to be related to differential expression of cell survival or cell death genes and signaling. These differences alone could render the CA1 region more vulnerable to aging. Because of these regional differences, a number of investigators have examined the role of subfield-specific gene expression in cognitive aging using microarray technology. In this review, I will discuss the main findings of these genome studies as they relate to the cognitive impairments associated with aging.

As the study of hippocampal aging progresses, it is becoming clear that most, if not all, of these age-related changes reflect adaptations that selectively vary by the type and degree of change; along with the specific hippocampal region affected. It is not clear whether these adaptations represent a response to ongoing damage and whether compensatory mechanisms are required for successful aging. In any case, there are a vast number of reports that describe and categorize the nature of these adaptations and a comprehensive review of this literature is not possible in this chapter. Deficits in biophysical properties, morphology, and information processing in the various regions of the aging hippocampus have been discussed extensively in recent years. Therefore Section "Age-Related Morphological and Plasticity Changes are Region-Specific and Correlate with Cognitive Impairment" presents a general description of the literature. For more detailed information, the reader is directed to comprehensive reviews on these subjects (Burke and Barnes, 2006; Wilson et al., 2006; Disterhoft and Oh, 2007; Thibault et al., 2007; Kumar et al., 2009; Lister and Barnes, 2009; Oh et al., 2010). This review focuses on select categories of age-related molecular changes that characterize individual hippocampal subfields and describes how these changes correlate with cognitive ability.

\section{AGE-RELATED MORPHOLOGICAL AND PLASTICITY CHANGES ARE REGION-SPECIFIC AND CORRELATE WITH COGNITIVE IMPAIRMENT}

As mentioned earlier, cognitive aging does not result in loss of existing adult hippocampal neurons per se (Rasmussen et al., 1996; Rapp et al., 1999). Instead, changes in neuronal morphology have been reported, and these alterations are region-specific. For example, aging is associated with a loss of synaptic contacts in the subiculum (Uemura, 1985) but not in other hippocampal regions (Curcio and Hinds, 1983; Hanks and Flood, 1991; Markham et al., 2005).

Within the hippocampus, anatomical changes have been linked to cognitive decline. Individual variability in memory impairment occurs with age, and this phenomenon has been described in different species including rodents and humans (Gage et al., 1984; Gage and Bjorklund, 1986; Rapp et al., 1987; deToledo-Morrell et al., 1988; Aitken and Meaney, 1989; Markowska et al., 1989; Lindner et al., 1992; Gallagher et al., 1993; van der Staay and de Jonge, 1993). Spatial memory tasks like the Morris water maze (MWM; Morris, 1984) have been used to sort aged rats into learning-impaired (AI) and learning-unimpaired (AU) relative to young rats $(\mathrm{Y})$, as a model of the cognitive impairments found in aged humans (for reviews see Gallagher and Nicolle, 1993; Rosenzweig and Barnes, 2003).

Specific anatomical changes associated with cognitive impairment have been studied in sub-regions of the hippocampus. While learning impairments are not associated with a loss in the total number of synapses in the CA1 region (Geinisman et al., 2004), a decrease in the area of perforant path synapses of AI animals suggests that hippocampal perforated synapses become less efficient in AI animals (Nicholson et al., 2004). Perforated synapses are believed to represent activated synaptic transmission sites (Geinisman et al., 1993; Buchs and Muller, 1996; Toni et al., 1999). Similarly, in the CA3 area, aging does not result in synapse density loss (Poe et al., 2001). Instead, cognitive impairments have been associated with a decrease in the presynaptic elements involved in connectivity, as revealed by decreases in expression of the vesicle marker synaptophysin in the CA3 of AI animals (Smith et al., 2000). A decrease in perforant path input to the dentate gyrus (Geinisman, 1979; Rogalski et al., 2009) has been linked to aging. These alterations correlate with cognitive impairments (Geinisman et al., 1986; Smith et al., 2000) and are accompanied by physiological compensatory changes that will be described below.

Since the 1980s, several groups have shown that deficits in synaptic plasticity occur in the hippocampus during aging (Barnes and McNaughton, 1980; Deupree et al., 1993; Moore et al., 1993; Norris et al., 1996); reviewed in (Lister and Barnes, 2009). Studies 
indicate that senescence affects some of the properties of LTP and long-term depression (LTD). In addition to general age-related changes in synaptic plasticity, differences in plasticity properties have been identified between aged animals that were categorized as AU or AI relative to Y (Bach et al., 1999; Schulz et al., 2002; Tombaugh et al., 2002; Lee et al., 2005; Foster and Kumar, 2007; Boric et al., 2008). First, cognitive impairments are associated with a lower threshold for induction of LTD in the CA3-CA1 synapse (Foster and Kumar, 2007), although a different study indicated that a shift to NMDA-independent LTD in the Schaffer collateral to CA1 synapse is associated with superior learning in aged rats (Lee et al., 2005). The discrepancies are probably due to technical differences in the LTD protocols and behavioral paradigms used in the two studies. While the study by Foster and Kumar (2007) classified animals based on memory impairments, Lee et al. (2005) examined learning impairments.

Similarly, distinct LTP induction parameters have been used to identify plasticity deficits that correlate with learning impairments in aged individuals. For example, Tombaugh et al. (2002) reported that a theta-frequency stimulation paradigm but not a higher frequency stimulation (HFS) protocol was able to distinguish AU vs. AI animals. Under these LTP induction conditions, significantly lower synaptic potentiation in area CA1 was detected in AI rats relative to AU and $\mathrm{Y}$ animals (Tombaugh et al., 2002). This lower LTP expression level was not due to a loss of NMDA receptor function. A different group reported that while reduction of LTP magnitude was associated with aging, it did not correlate with behavior performance in aged rats. Instead, a shift to a non-NMDAdependent LTP was reported (Boric et al., 2008). Enhancement of voltage-gated calcium channel (VGCC) LTP was characteristic of aged unimpaired animals relative to AI and Y. Lastly, groups using a HFS protocol, reported decreases in LTP in aged mice and rats with impaired spatial memory performance (Bach et al., 1999; Schulz et al., 2002). This HFS protocol is known to depend both on NMDA receptor and VGCC activation (Grover and Teyler, 1990), but the Bach et al. (1999) and Schulz et al. (2002) studies did not determine which of these components contributed to the alterations in LTP expression. Overall, these selective changes in LTP and LTD that differentiate superior learners from learning-impaired aged subjects exemplify the type of physiological compensatory changes that might reflect successful learning in aged animals.

Furthermore, disruption in calcium homeostasis and aging have been well studied (reviewed extensively by Thibault et al., 2007; Kumar et al., 2009). In terms of cognitive aging, calcium dysregulation results in changes in cell excitability and synaptic plasticity which could represent the cellular basis for the learning impairments associated with aging. Age-related plasticity changes in intrinsic excitability, as measured by the postburst afterhyperpolarization (AHP), have been reviewed in this special issue of Front. Ag. Neurosci. (Oh et al., 2010).

Finally, age-related alterations in information processing by place cells occur in selective hippocampal areas (Barnes et al., 1997; Shen et al., 1997; Wilson et al., 2005; reviewed in Wilson et al., 2006). For example, recordings of cell activity in freely moving rats indicate that rapid, experience-dependent plasticity is disrupted in CA1 during aging (Tanila et al., 1997; Oler and Markus, 2000; Burke et al., 2008; Sava and Markus, 2008). In addition, aged CA3 place cells show rigidity in their ability to form new spatial representation (Wilson et al., 2005). One outcome of these age-related alterations is that the extent of impairment in forming new spatial representations correlates with spatial memory impairments (Tanila et al., 1997; Wilson et al., 2003).

\section{AGE-ASSOCIATED DECREASE IN ADULT NEUROGENESIS IN THE DENTATE GYRUS AND ITS POTENTIAL ROLE IN COGNITIVE DECLINE}

Because of the discovery of adult neurogenesis in the dentate gyrus, this hippocampal region has received special attention (Altman and Das, 1965; Cameron et al., 1993; Kuhn et al., 1996). Adult neurogenesis entails several cellular processes that begin with the proliferation of progenitor cells in the subgranular zone (Seri et al., 2004). These cells extend axons rapidly (Hastings and Gould, 1999). New cells migrate from the hilar region or subgranular zone to the granule cell layer by 17 days after cell division, but do not acquire their final mature neuronal phenotype and morphology until about 4 weeks (Altman and Das, 1966; Cameron et al., 1993; Cameron and McKay, 1999). Then it takes 4-7 weeks for the cells to develop the electrophysiological properties necessary for the formation of functional connections (van Praag et al., 2002). In addition to these neurodevelopmental steps, to maintain a constant rate of cell turnover, equilibrium between neurogenesis and cell death must be established. It appears that this equilibrium is important for learning (Dupret et al., 2007).

Neurogenesis in the hippocampus declines with age (Seki and Arai, 1995; Kuhn et al., 1996; Lemaire et al., 2000; Lichtenwalner et al., 2001; Rao et al., 2005; Olariu et al., 2007). During aging, the decrease in neurogenesis is a result of several factors that include: (1) a reduction in the rate of proliferation of neural progenitor cells (Kuhn et al., 1996; Cameron and McKay, 1999; Heine et al., 2004; McDonald and Wojtowicz, 2005; Rao et al., 2005; Walter et al., 2009), (2) a decrease in the overall number of progenitor cells (Olariu et al., 2007), and (3) a drop in the number of progenitor cells that mature into a neuronal phenotype (Kempermann et al., 1998; van Praag et al., 2005). Age-related changes seem to reflect alterations in the expression of sets of genes that dictate the development and timing of neurogenesis and the balance between neurogenesis and cell death (Burger et al., 2008). Even though there is a decrease in neurogenesis associated with aging, the remaining newly generated neurons in the aged dentate display the same densities of dendritic spines and afferent glutamatergic connections as newly generated neurons in young animals (Morgenstern et al., 2008).

Mounting evidence indicates that neurogenesis in this region of the hippocampus plays a role in learning and memory (Gould et al., 1999; Shors et al., 2001; Dupret et al., 2007, 2008). For example, some reports indicate that neurogenesis is important for learning in young animals (Gould et al., 1999; Shors et al., 2001; Kempermann and Gage, 2002; Dobrossy et al., 2003). Yet, despite this evidence, other reports present conflicting views, namely, that neurogenesis does not have an effect on spatial learning (Shors et al., 2002; Madsen et al., 2003; Raber et al., 2004; Van der Borght et al., 2005; Leuner et al., 2006; Dupret et al., 2008). The conflicting results might be due to the varying degrees of hippocampal demand required by each of the behavioral tasks used. For example, Dupret et al. (2008) found no effect when simple spatial learning paradigms were used such as habituation to a novel environment or contextual fear conditioning. 
On the other hand, the more complex spatial relational learning (spatial navigation in the water maze) was dependent on adult neurogenesis in this study (Dupret et al., 2008). In contrast to this study, other groups have reported no effect of neurogenesis on performance in the MWM (Shors et al., 2002; Madsen et al., 2003; Raber et al., 2004; Snyder et al., 2005).

To complicate this issue further, the relationship between neurogenesis, learning and memory and aging is even less clear. Although neurogenesis in the dentate declines with age (Seki and Arai, 1995; Kuhn et al., 1996; Lemaire et al., 2000; Lichtenwalner et al., 2001; Rao et al., 2005; Olariu et al., 2007), it still has not been clearly demonstrated that neurogenesis correlates with learning ability in aged rodents (Bizon and Gallagher, 2003, 2005; Merrill et al., 2003; Walter et al., 2009). However, evidence from other laboratories indicates that a correlation between neurogenesis, aging and learning does exist (Cameron and McKay, 1999; Drapeau et al., 2003; Aizawa et al., 2009). Regarding these latter studies, only the Drapeau et al. (2003) study segregated aged individuals into AU and AI. Explanations for these discrepancies range from technical differences in the timing and methods for counting cells, to the type of hippocampal-dependent memory tasks used (Cameron and McKay, 1999; Dobrossy et al., 2003; Leuner et al., 2009). Also, different rates of functional maturation of newly generated cells have been observed in mice and rats (reviewed in Drapeau and Nora Abrous, 2008). Moreover, these techniques have been used to address two different questions. Namely, is neurogenesis necessary for learning? (Kempermann and Gage, 2002; Drapeau et al., 2003) or, does learning increase neurogenesis? (Gould et al., 1999; Ambrogini et al., 2000; Dobrossy et al., 2003; reviewed in Leuner et al., 2006). Finally, neurogenesis displays anatomical gradients such that the rate of neurogenesis is higher in the temporal portion of the hippocampus, known to be involved in non-spatial learning. This would explain how specific hippocampal behavioral phenotypes such as anxiety-related behavior or other non-spatial aspects of hippocampal function are affected by neurogenesis (Snyder et al., 2009a,b,c). Future research involving simple and complex hippocampal-dependent tasks in the study of cognitive aging and neurogenesis should help resolve this debate.

The studies discussed in this section suggest that deficits in connectivity, synaptic plasticity, and neurogenesis are associated with cognitive decline in senescence. These processes are likely to involve increases or decreases in the expression of genes that directly participate in these functions (e.g., genes that regulate cell shape, membrane channels, signaling cascades). This next section discusses aging and learning gene expression changes that might explain the functional decline described at the cellular and systems level.

\section{SUB-REGIONAL DIFFERENCES IN GENE EXPRESSION CORRELATE WITH COGNITIVE AGING}

The molecular mechanisms underlying age-related learning impairments are not well understood. Questions remain concerning whether cognitive decline results from the dysregulation of molecular pathways normally employed by younger animals. Further, it is unclear whether the molecular changes are compensatory or pathological. It is widely accepted that learning, memory formation, and synaptic plasticity involve the activation of numerous genes and signaling cascades (Lee and Silva, 2009; Richter and Klann, 2009).
The development of microarray technology has allowed scientists to interrogate the entire genome regarding the changes in expression of thousands of genes. For this reason, this technology has been used to explore the genes and pathways involved in rodent models of learning and memory formation both in the young (Cavallaro et al., 2001; Luo et al., 2001; D'Agata and Cavallaro, 2003; Leil et al., 2003; Robles et al., 2003; Haberman et al., 2008) and aged hippocampus (Blalock et al., 2003; Verbitsky et al., 2004; Burger et al., 2007, 2008; Cheng et al., 2007; Rowe et al., 2007; Stranahan et al., 2008; Aenlle et al., 2009; Haberman et al., 2009; Kadish et al., 2009; Pawlowski et al., 2009). In this section, I will discuss how gene expression differences across hippocampal regions of aged individuals relate to cognitive status.

Table 1 summarizes the hippocampal expression analyses that have been carried out by various laboratories to identify changes in age-related gene expression that correlate with cognitive ability. Based on the results from these groups, it is difficult to construct a general mechanism for hippocampal cognitive aging. As illustrated in Table 1, one limitation to comparing microarray studies of complex behaviors is that diverse experiments involve different animal strains, training regimens, experimental controls, dissection methods, times of analysis following learning tasks, and stringency and type of statistical analysis. More importantly, the analyses in these reports were tailored to answer different questions. Some were designed to look at chronological changes in the hippocampus and how those correlate with learning performance (Blalock et al., 2003; Kadish et al., 2009) while others were specifically devised to identify genes that were altered at different points after learning (Burger et al., 2007, 2008; Rowe et al., 2007). Yet others were planned to examine basal differences in expression associated to cognitive status (Verbitsky et al., 2004; Haberman et al., 2009; Pawlowski et al., 2009). Another factor that makes between-studies comparison difficult is the fact that the functional groups used by the various bioinformatic engines are sometimes too broad and therefore uninformative. As examples, "transcription factors/transcription translation" and "signal transduction" were common to a number of studies.

In spite of all these caveats, a few common pathways have been identified in the various studies discussed in this section (Table 1; in Bold). As an example, the various studies carried out by the Landfield group (Blalock et al., 2003; Kadish et al., 2009; Rowe et al., 2007) identified common pathways that include inflammation/immune genes and an activation of myelogenic/oligodendrocytic genes involved in myelination. Verbitsky et al. (2004) and Haberman et al. (2009) also described immune and inflammation functions to be associated with cognitive deficits. In addition, genes involved in cholesterol metabolism and phospholipid trafficking were correlated with cognitive aging (Blalock et al., 2003; Rowe et al., 2007; Kadish et al., 2009). Iron homeostasis was found to be upregulated in Verbitsky et al. (2004), as well as in Rowe et al. (2007) and appears to regulate myelin metabolism. Examples of other functional groups include genes related to synaptic transmission and morphology, and neurogenesis. The rest of this section discusses in detail the results from genome-wide studies of cognitive aging that provide a link between the differential expression observed at the molecular level and the alterations observed as a result of cognitive aging at the cellular and anatomical level. 
One of the first genomic studies addressing the effects of hippocampal aging and cognition at the genome level was carried out by the Landfield group (Blalock et al., 2003). This study assessed alterations in gene expression in young (4-month-old), middleaged (14-month-old), and aged rats (24-month-old). Because the researchers recognized that there are selective differences between hippocampal subfields they focused on changes in the CA1 region. Aged rats were not categorized into AI or AU prior to microarray analysis. Instead, aging and cognition genes were identified using correlation analysis of aging genes that were associated with cognitive impairment.

This analysis identified a number of genes that correlate with cognitive aging. These aging and cognition regulated genes (ACRG) were categorized under different functional categories developed by the group. Seven of the functional categories contained downregulated genes and ten functional categories had upregulated genes. Those categories with downregulated genes described synthetic, metabolic, protein folding, and synaptic plasticity functions. These included genes involved in biosynthesis and energy metabolism, in particular genes involved in mitochondrial function and electron transport. Other downregulated ACRGs that are interesting in this context were involved in activity-dependent synaptic and neurite plasticity. The last functional category of downregulated genes reported by this group included those that code for chaperone proteins. Functional categories that showed increased expression included ACRGs associated with glial function, inflammation, oxidative stress, as well as genes involved in myelin, cholesterol, and lipid metabolism. Genes related to growth and protein synthesis, as well as protein and vesicle trafficking were found to be upregulated and a number of these genes are important in myelin synthesis and transporting myelin vesicles in oligodendrocytes. This list of upregulated ACRGs contained a large number of immune genes including major histocompatibility complex class I antigen presenting molecules. Moreover markers for activated astrocytes also showed increased expression. Genes involved in metabolism of amino acids that are important for lipogenesis and energy metabolism were also upregulated. Iron utilization genes important for response to oxidative stress, inflammatory responses belong to this group. In general, upregulated genes corresponding to stress and immune/inflammation were over-represented.

According to the authors, all these changes could reflect decreased metabolic and biosynthetic processes occurring in tandem with gene expression changes signifying increased myelin turnover, phagocytosis, and inflammation in glial cells. Taken together, the results suggest that demyelination may be occurring. Demyelination may in turn affect cognitive processes by disrupting neurotransmission (Table 1). This study revealed that while cognitive impairments occur late in life, the transcriptional changes were identified in midlife. Namely, the changes in specific ACRG that correlated with cognitive deficits in 24-month animals were found to begin in middle age (14-month) and the expression differences continued to increase between middle age to 24 months.

In regard to this point, it is important to note that all the microarray studies discussed in this review investigated learning/acquisition rather than memory consolidation (see Table 1). Previous research has shown that while learning impairments occur late in life (22-24 months), impaired memory consolidation can occur in midlife (12 months) (Bizon et al., 2009). At this point, no genomewide analyses of memory-formation/consolidation associated with aging have been carried out.

A later report from the Landfield group examined the progression of the transcriptional changes in the hippocampus across the adult lifespan (Kadish et al., 2009; Table 1). The authors examined five age groups, 3-, 6-, 9-, 12-, and 23-month-old F344 rats. They assigned gene changes to four groups based on the age of onset of gene expression changes. The four groups included: early adult-onset (changes observed between 3 to 6 months), intermediate onset (changes observed between 6 and 9 months), midlife onset (changes observed between 9 and 12 months), and late onset (changes observed between 12 and 23 months).

Early adult-onset group genes that were upregulated included those associated with ribosomal assembly, lysosomal, stress/inflammatory, and protein/lipid degradative pathways. Downregulated functions included genes involved in neuronal development and energy-dependent signaling protein genes that are important for lipid and cholesterol synthesis. Cytokine, immune and inflammatory, as well as proteolytic pathways were affected in the intermediate onset group as evidenced by downregulation of genes for pathway proteins. Functional categories that were downregulated included genes involved in ion channel and vesicle transport. From their data, the authors concluded that cognitive impairments began in the midlife-onset age group. Not surprisingly, this age range included the highest number of upregulated genes that correlated with cognitive impairments. The upregulated genes corresponded to astrocyte reactivity and cytoskeletal structure along with cation and iron homeostasis (involved in myelogenesis). Lipid metabolism related genes were also upregulated, in particular genes involved in cholesterol and phospholipid trafficking. Inflammation and immunity genes were also found to be upregulated in this age range, specifically genes important for antigen-presentation. Downregulated genes included those for proteins involved in energy-dependent pathways (GTP, ATP), vesicle transport, neurite outgrowth and GTPase activity. In the last group of animals, those with late onset gene expression changes and cognitive impairment, genes for immune and inflammatory processes and those involved in ribosome synthesis and cell proliferation were upregulated. Downregulated genes included those for cytoskeletal proteins, ATP-GTP dependent signaling molecules. The authors observe that expression differences at this stage appear to be part of a continuum of changes that were initiated in younger animals.

In conclusion, this report put forth the hypothesis that sequential changes in biological pathways across the lifespan of an animal trigger cumulative damaging functions that set the stage for cognitive aging. The transcriptional changes correlating with decreased cognitive function are first observed during midlife (9-12 months). Namely, metabolic changes in lipid and ketone body oxidation lead to inflammatory processes that degrade myelin and produce excess cholesterol. In turn, excessive cholesterol increases cholesterol transport to promote myelogenesis. Together, these energyconsuming molecular events damage neuronal and glial structure and function and result in impaired cognitive function.

In a different study, Verbitsky et al. (2004), identified a small set of genes (35) that were differentially expressed between young and aged mice that had been trained in a spatial learning task. The 
Table 1 | Summary of gene profiling studies assessing age-related cognitive decline in the hippocampus.

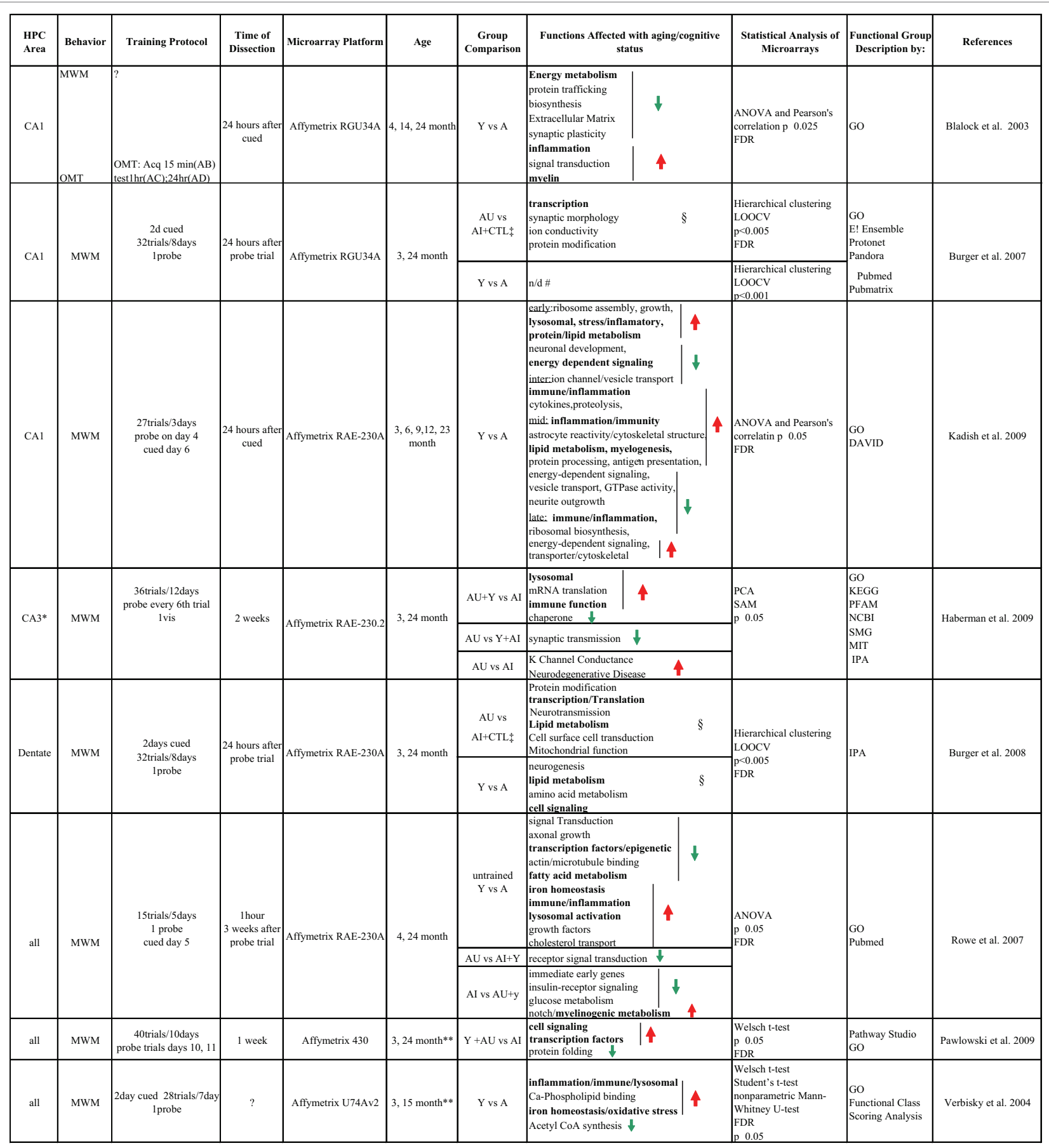

All studies referenced in this table used one microarray chip per animal which permits attributing a molecular profile to a given subject's behavioral ability. Bold indicates functional groups that have been recognized to be common to several microarray studies. Red and green arrows represent upregulated or downregulated functions, respectively.

*The authors examined CA1, CA3, and dentate, but focused on CA3 gene changes.

**These experiments were carried out in mice while the rest of the experiments in the table were carried out in rats.

${ }^{\ddagger} \mathrm{CTL}=$ aged controls for stress, exercise and non-spatial aspects of learning.

${ }^{*}$ Listed genes but did not classify into functional groups.

${ }^{s}$ The genes in various categories were upregulated or downregulated but the changes in the entire functional groups were not determined.

SAM, Significance Analysis of Microarrays (www.stat.stanford.edu/ tibs/SAM/); FDR, false discovery rate; PCA, principal component analysis; LOOCV leave-one-outcross-validation (nearest neighbor prediction model); OMT, object memory task (A, B, C, D, refer to different objects); GO, Gene Ontology (www.geneontology.org/; Pathway Studio, www.ariadnegenomics.com/products/pathway-studio); DAVID, Database for Annotation, Visualization and Integrated Discovery (www.david.abcc. ncifcrf.gov); KEGG, Kyoto Encyclopedia for Genes and Genomes; SMG, Stanford Microarray Group (www.stat.stanford.edu/ TIBS/GSA); MIT, Broad Institute at MIT (www.broad.mit.edu/gsea/downloads.jsp); IPA, Ingenuity Pathway Analysis (www.ingenuity.com). 
majority of the genes (82\%) were upregulated with aging (Verbitsky et al., 2004) Using Gene Ontology (GO), they identified a number of top scoring functional classes that included genes for immune/ inflammation/lysosomal endopeptidases, followed by iron homeostasis, acetyl-CoA biosynthesis, and calcium-phospholipid binding. The authors suggest that the inflammatory gene changes are markers for neurodegeneration while iron homeostasis is involved in oxidative processes. Further, they argue that the change in acetylCoA biosynthesis is important for cognition because it is not only involved in energy production, but also in acetylcholine production in cholinergic neurons. This assertion is supported by other work that demonstrates that this pathway is downregulated in cognitive aging (Decker et al., 1988; Casu et al., 2002).

It should be noted that aged individuals in the three studies just discussed (Blalock et al., 2003; Verbitsky et al., 2004; Kadish et al., 2009) were not classified into AU/AI. Cognitive status was tested in young, middle-aged, and aged animals and correlated with aging-related genes. In the various studies, middle-age subjects (12 months) showed cognitive impairments when compared to young adults. Because of this experimental design, these studies describe molecular cognitive aging as a general phenomenon, but they cannot be used to explain how individual differences in cognitive outcomes occur in the aged population.

A number of genomic studies have employed a more discriminating behavioral model to investigate gene expression differences in aged animals. These studies distinguish between aged animals that can learn a spatial task (AU) relative to those who are unable to learn (AI), and to young rodents (Table 1; Burger et al., 2007, 2008; Rowe et al., 2007; Haberman et al., 2009; Pawlowski et al., 2009). Three very distinctive molecular signatures become apparent in these analyses. First, molecular profiles arise that distinguish young animals and aged animals, independent of their cognitive ability. A second pattern emerges that is composed of genes shared by young and aged unimpaired animals. Third, groups of genes appear that may represent markers for successful cognitive aging, that is, genes that are unique to aged unimpaired animals. These three patterns of expression are discussed below.

\section{Al + Y VS. AU: ARE ADAPTIVE MOLECULAR MECHANISMS INVOLVED IN SUCCESSFUL COGNITIVE AGING?}

An important result from the diverse studies that have examined aging and cognitive abilities is the evidence that in all hippocampal fields, a large number of genes are differentially expressed due to senescence - irrespective of cognitive abilities (Blalock et al., 2003; Burger et al., 2007, 2008; Rowe et al., 2007; Haberman et al., 2009; Kadish et al., 2009; Pawlowski et al., 2009). The data from these studies indicate that the molecular environment of the young hippocampus is different from that found in the aging hippocampus (see also Wei et al., 1999; Lukiw, 2004). Therefore, one might predict that the genes that are important in successful learning in aged animals may differ from those utilized by young adults. Indeed, a number of genes in CA3 that correlate with successful learning in aged animals are distinct from those found both in young and aged impaired (Haberman et al., 2009). In this study sixty percent of the genes that were different between $\mathrm{AU}$ and $\mathrm{AI}+\mathrm{Y}$ were downregulated in AU subjects when compared to $\mathrm{AI}+\mathrm{Y}$. Of the 289 probe sets identified in this analysis, the authors discuss only one functional group that includes genes involved in synaptic transmission. Their data from the CA3 region is in agreement with our findings in both the CA1 and dentate gyrus, where aged animals that had successfully learned the MWM did not show the same patterns of gene expression as trained young animals (Burger et al., 2007, 2008). In further support of the idea that AU animals employ a different molecular strategy than AI or Y animals, when Rowe et al. (2007), analyzed the entire hippocampus, they found that genes involved in receptor signal transduction were upregulated in AU animals relative to $\mathrm{AI}+\mathrm{Y}$.

\section{AU + Y VS. AI: EVIDENCE OF MOLECULAR PROFILES THAT IDENTIFY COGNITION GENES THAT ARE IMPORTANT BOTH EARLY IN LIFE AND WITH SENESCENCE}

The second pattern of expression when assessing $\mathrm{Y}, \mathrm{AU}$, and $\mathrm{AI}$ animals represents a set of cognition genes that are important in young animals that become dysregulated in aged cognitive-impaired animals (Rowe et al., 2007; Haberman et al., 2009; Pawlowski et al., 2009). In this case, AU animals show patterns similar to trained young animals in all sub-regions of the hippocampus analyzed. Two groups have found that differences in gene expression occur between $\mathrm{AU}$ and $\mathrm{AI}$ when same age cohorts are compared (Burger et al., 2007, 2008; Haberman et al., 2009; see Sub-regional Differences in Gene Expression Correlate with Cognitive Aging).

Rowe et al. (2007) investigated the changes that occurred in the hippocampus at the end of training (day $5 \mathrm{~T}$ ) or 21 days post training (21PT) in AU and AI animals when compared to young rats in the entire hippocampus. When they evaluated the genes that were differentially expressed in AI relative to AU and Y, they found a number of downregulated gene categories that included G-protein-coupled receptors, organogenesis (this category included a number of immediate early genes), insulin pathways, glucose utilization, and lipogenesis. There were also some upregulated functional categories that included oxidoreductase activity, and notch signaling. This pathway is important in developmental and differentiation processes, and was also found to be upregulated 21 days after training. At 21 days, G-protein coupled receptors, lipogenic, growth regulation and calcium channel genes were downregulated. Upregulated genes included pathways involved in organogenesis. A number of myelin/oligodendrocyte related genes were also differentially expressed.

Because this study analyzed two time points after training, it allowed the authors to analyze the training dependence of the molecular changes observed. The authors found that downregulated pathways in AI animals decreased under training (day 5) and then recovered to AU levels at day 21PT. These pathways included IEG/ growth and glucose utilization/insulin signaling pathways. These pathways showed stable expression levels in both AU and Y rats. On the other hand, pathways that were upregulated in AI processes kept their high levels of expression at day 21PT. These pathways included notch signaling and myelinogenesis. This study concludes that AI animals show glucose utilization deficits during learning, leading to downregulation of energy-consuming pathways that usually afford plasticity mechanisms. This in turn activates stress signals that activate inflammatory and myelogenic pathways.

Haberman et al. (2009) analyzed the three hippocampal regions in $\mathrm{AU}+\mathrm{Y}$ and $\mathrm{AI}$ animals. They found the most significant changes in expression across all of the groups analyzed occurred in the CA3 region. Both the CA1 and the dentate showed less accentuated 
changes in age-cognitive gene expression. This is the only microarray study that has been carried out in the aged CA3, so it is not possible to corroborate this observation with other microarray studies. Based on the fact that Haberman et al. (2009) found a larger number of genes altered in CA3, they focused on this region with the gene function analysis. Analysis of the CA3 subfield revealed that impaired spatial learning was associated with increased expression of genes involved in lysosome function, immune function, and mRNA translation. These changes were found to be common to other sub-regions. CA3-specific expression changes associated with cognition included a decrease in expression in genes involved in chaperone and protein folding functions. This study shows that each hippocampal sub-region dysplasia characteristic, region-specific expression pattern in association with the cognitive status of the animal. This is in agreement with our studies where we found no overlap between the genes identified in CA1 and the dentate region (Burger et al., 2007, 2008). Therefore, at the molecular level, these microarray studies by Burger et al. $(2007,2008)$ and Haberman et al. (2009) corroborate evidence regarding the distinctive roles played by each sub-region in spatial learning.

The third genome-wide study that analyzed differences between $\mathrm{AU}+\mathrm{Y}$ relative to $\mathrm{AI}$ also looked at the entire hippocampal formation (Pawlowski et al., 2009). They distinguished 19 impairmentrelated genes that could be classified into three functional groups. These included transcription factors, protein folding and cell signaling pathways. It is surprising that at the statistical significance level they used ( $p \leq 0.05$ ), the authors only identified 19 genes.

\section{AI VS. AU: GENES THAT CHARACTERIZE AGED SUBJECTS WITH SUPERIOR COGNITIVE ABILITIES}

Two genome-wide analyses have carried out the AU vs. AI comparison. Haberman et al. (2009) performed the analysis of the CA1, CA3 and dentate region. Burger et al. $(2007,2008)$ performed this analysis of $\mathrm{AU}$ vs. $\mathrm{AI}$ in the $\mathrm{CA} 1$ region and in the dentate. The results of the analyses are discussed below by anatomical region.

\section{Functional Pathways Differentially Expressed in the CA1 between AI and $A U$}

Our AU vs. AI comparison in CA1 revealed a set of genes that could be classified into the following functions: transcription, synaptic morphology, ion conductivity and protein modification (38 genes; Burger et al., 2007). The majority of the genes included in these categories were upregulated in AI subjects. On the other hand, Haberman et al. (2009) found that genes in the Erk/AKt-Mapk3 signaling pathway differed between AU and AI rats (20 genes). So, it appears that the two studies identified different functional groups associated with successful learning in aged rats. One reason for this difference could be that our study included non-learning aged controls in our AI group. This strategy eliminated contributions from stress, motor activity, or basal differences to the training paradigm that could confound expression differences between AU and AI. Another reason for the differences could be attributed to the fact that we dissected the hippocampus $24 \mathrm{~h}$ after training to study differential expression changes that occurred as a consequence of learning. Haberman et al. (2009) dissected the CA1 sub-region at 21 days after behavior, looking for basal levels of gene expression that differentiate AU relative to AI. The individual genes identified in the Haberman et al. (2009) analysis for this hippocampal subfield were not listed in the study, so it is not clear if there is an overlap between some individual genes identified in the Burger et al. (2007, 2008) and the Haberman et al. (2009) studies.

\section{Changes in Expression Profiles between AU and Al in CA3}

Only Haberman et al. (2009) have investigated the molecular pathways of CA3 in AU and AI rats. The Ingenuity Pathway analysis identified amyloid precursor protein signaling and the potassium channel signaling pathways as highly significant and downregulated in $\mathrm{AU}$ animals. In addition, calcium signaling, vesicular transport and release, MAP Kinase, and $\mathrm{PKC} / \mathrm{p} 38$ signaling pathways were also found to be differentially expressed in AU animals when compared to AI (Table 1).

\section{Differences in Expression Profiles between AU and Al in the Dentate Gyrus}

In the Haberman et al. (2009) study, genes for cell morphology and nervous system function pathways were significantly different between AU and AI. Our analysis of the dentate gyrus identified six functional groups that included protein modification, transcription/translation, neurotransmission, lipid metabolism, cell surface/ cell transduction, and mitochondrial function.

Together, these studies suggest that "adaptive" gene expression changes occur in association with successful cognitive aging. The adaptive process maybe compensatory. For example, overcoming age-related changes in connectivity through expression of genes related to morphology in CA3 and neurotransmission in the dentate gyrus. Alternatively, these adaptive changes maybe intrinsic to the maturation process of the brain. That is, aged unimpaired individuals may show specific gene changes because previous experience modifies the way an individual learns. According to this idea, learning in young animals is not necessarily more efficient, but simply different from older animals. It is possible that when learning occurs on the backdrop of greater experience and more "practice" with the process of learning, that the molecular processes involved assume a different character. In the case of aged impaired animals, this adaptation due to previous experience may have degraded.

It should be noted that the learning impairments found in aged rodents can be overcome by multiple training sessions (Rapp et al., 1987). This suggests that the capacity for learning is not lost, only deteriorated. Therefore, it would be interesting to elucidate whether the patterns of gene expression in AI after extensive training become more like the gene expression profiles identified in the animals that do learn with fewer trials (AU and $\mathrm{Y}$ ).

Key conclusions from these genome-wide studies on cognitive aging are (1) there are a number of genes that are common to young individuals and aged individuals with preserved performance and (2) there are also some molecular profiles that are uniquely found in animals exhibiting successful cognitive aging. This latter set of genes might yield important clinical markers and/or yield therapeutic targets for age-associated memory impairments. Microarray analysis provides both the tools and the groundwork for the development of hypothesis-driven functional validation studies to confirm the roles of potential molecular pathways identified with genomic technology. To determine how these genes and pathways are co-regulated will require future research using various molecular biology and 
genetic approaches such as the use of transgenic technology (Havekes and Abel, 2009) and viral and non-viral gene targeting (Burger et al., 2005; Jerusalinsky and Epstein, 2006; Lundberg et al., 2008; Schubert et al., 2008; Southgate et al., 2008).

\section{CONCLUSION}

The aging hippocampus does not appear to show a major loss of cells or alterations in morphology. Instead, it is characterized by differential regulation of gene expression. In turn, these changes in gene expression may result in functional modifications, for example, changes in receptors and ion channels that can lead to changes in the synaptic properties of hippocampal cells, or changes in structural proteins that might alter the morphology of the dendritic spines. Examination of the patterns in data describing different groups of aged animals suggests evidence of "adaptive" strategies associated with aging and learning at the molecular, cellular and behavioral levels. For example, in terms of behavior, the use of different age-dependent learning strategies has been reported in rodents (Clark et al., 1992; Schulz et al., 2002; Tombaugh et al., 2002; Burger et al., 2007). In other words, memory-unimpaired aged learners use different tactics than younger animals to successfully complete a learning task. In addition, at the cellular level, both LTP and LTD can distinguish between aged learning-unimpaired vs. learning-impaired animals, when compared to young rats (Tombaugh et al., 2002; Lee et al.,

\section{REFERENCES}

Adams, M. M., Smith, T. D., Moga, D., Gallagher, M., Wang, Y., Wolfe, B. B., Rapp, P. R., and Morrison, J.H. (2001). Hippocampal dependent learning ability correlates with $\mathrm{N}$-methyl-Daspartate (NMDA) receptor levels in CA3 neurons of young and aged rats. J. Comp. Neurol. 432, 230-243.

Aenlle, K. K., Kumar, A., Cui, L., Jackson, T. C., and Foster, T.C. (2009). Estrogen effects on cognition and hippocampal transcription in middle-aged mice. Neurobiol. Aging 30, 932-945.

Aitken, D. H., and Meaney, M. J. (1989). Temporally graded, age-related impairments in spatial memory in the rat. Neurobiol. Aging 10, 273-276.

Aizawa, K., Ageyama, N., Terao, K., and Hisatsune, T. (2009). Primate-specific alterations in neural stem/progenitor cells in the aged hippocampus. Neurobiol. Aging doi: 10.1016/j. neurobiolaging.2008.12.011. [Epub ahead of print].

Altman, J., and Das, G. D. (1965). Autoradiographic and histological evidence of postnatal hippocampal neurogenesis in rats. J. Comp. Neurol. 124, 319-335.

Altman, J., and Das, G. D. (1966). Autoradiographic and histological studies of postnatal neurogenesis. I. A longitudinal investigation of the kinetics, migration and transformation of cells incorporating tritiated thymidine in neonate rats, with special reference to postnatal neurogenesis in some brain regions. J. Comp. Neurol. $126,337-389$.

Amaral, D. G., and Lavenex, P. (2007). "Hippocampal neuroanatomy," in: The Hippocampus Book, eds P. Andersen, R. Morris, D. Amaral, T. Bliss, and J. O'Keefe (Oxford: Oxford University Press), 37-131.

Ambrogini, P., Cuppini, R., Cuppini, C., Ciaroni, S., Cecchini, T., Ferri, P., Sartini, S., and Del Grande, P. (2000). Spatial learning affects immature granule cell survival in adult rat dentate gyrus. Neurosci. Lett. 286 , 21-24.

Bach, M. E., Barad, M., Son, H., Zhuo, M., Lu, Y. F., Shih, R., Mansuy, I., Hawkins, R. D., and Kandel, E. R. (1999). Agerelated defects in spatial memory are correlated with defects in the late phase of hippocampal long-term potentiation in vitro and are attenuated by drugs that enhance the cAMP signaling pathway. Proc. Natl. Acad. Sci. U.S.A. 96, 5280-5285.

Ball, M. J. (1977). Neuronal loss, neurofibrillary tangles and granulovacuolar degeneration in the hippocampus with ageing and dementia. A quantitative study. Acta Neuropathol. 37, 111-118.

Barnes, C. A., and McNaughton, B. L. (1980). Physiological compensation for loss of afferent synapses in rat hip-

2005; Foster and Kumar, 2007; Boric et al., 2008). These studies have identified a switch from an NMDA-dependent synaptic plasticity in the young animals to a NMDA-independent plasticity in aged learning-unimpaired rats. Similarly, at the molecular level, differences in patterns of gene expression have been identified between aged learning-impaired and learning-unimpaired animals in the hippocampus when compared to young adults (Le Jeune et al., 1996; Smith et al., 2000; Burger et al., 2007, 2008; Rowe et al., 2007; Freeman et al., 2009; Haberman et al., 2009; Pawlowski et al., 2009).

The development of novel, effective therapeutics for age-related cognitive impairments is critically dependent on the identification of new molecular targets. Therefore, a major goal of molecular aging research is to derive a list of high impact genes that can potentially be used as the basis for drug targets and the design of new therapeutics for age-related memory impairments. Knowledge obtained from this research may result in treatments for memory loss, either by facilitating the discovery of drugs that specifically target the age-altered or -impaired genes/pathways, or by aiding efforts to modify expression of these putative memory genes.

\section{ACKNOWLEDGMENTS}

The author would like to thank Dr. Margaret Velardo, the reviewers, and the editor, for their invaluable contributions to this manuscript.

pocampal granule cells during senescence. J. Physiol. 309, 473-485.

Barnes, C. A., Suster, M. S., Shen, J., and McNaughton, B. L. (1997). Multistability of cognitive maps in the hippocampus of old rats. Nature $388,272-275$.

Bizon, J. L., and Gallagher, M. (2003). Production of new cells in the rat dentate gyrus over the lifespan: relation to cognitive decline. Eur. J. Neurosci. $18,215-219$.

Bizon, J. L., and Gallagher, M. (2005). More is less: neurogenesis and agerelated cognitive decline in LongEvans rats. Sci. Aging Knowledge Environ. 2005, re2.

Bizon, J. L., LaSarge, C. L., Montgomery, K. S., McDermott, A. N., Setlow, B. and Griffith, W. H. (2009). Spatial reference and working memory across the lifespan of male Fischer 344 rats Neurobiol. Aging 30, 646-655.

Blalock, E. M., Chen, K. C., Sharrow, K., Herman, J.P., Porter, N. M., Foster,T.C. and Landfield,P.W.(2003). Genemicroarrays in hippocampal aging: statistical profiling identifies novel processes correlated with cognitive impairment J. Neurosci. 23, 3807-3819.

Bonaventure, P., Guo, H., Tian, B., Liu, X., Bittner, A., Roland, B., Salunga, R., Ma, X. J., Kamme, F., Meurers, B. Bakker, M., Jurzak, M., Leysen, J. E., and Erlander, M. G. (2002). Nuclei and subnuclei gene expression profil- ing in mammalian brain. Brain Res 943, 38-47.

Boric, K., Munoz, P., Gallagher, M., and Kirkwood, A. (2008). Potential adaptive function for altered longterm potentiation mechanisms in aging hippocampus. J. Neurosci. 28, 8034-8039.

Brightwell, J. J., Gallagher, M., and Colombo, P. J. (2004). Hippocampal CREB1 but not CREB2 is decreased in aged rats with spatial memory impairments. Neurobiol. Learn. Mem. 81, 19-26.

Brizzee, K. R., and Ordy, J. M. (1979). Age pigments, cell loss and hippocampal function. Mech. Ageing Dev. 9, 143-162.

Buchs, P. A., and Muller, D. (1996). Induction of long-term potentiation is associated with major ultrastructural changes of activated synapses. Proc. Natl. Acad. Sci. U.S.A. 93, 8040-8045.

Burger, C., Cecilia Lopez, M., Feller, J. A., Baker, H. V., Muzyczka, N., and Mandel, R. J. (2007). Changes in transcription within the CA1 field of the hippocampus are associated with age-related spatial learning impairments. Neurobiol. Learn. Mem. 87, 21-41.

Burger, C., Lopez, M. C., Baker, H. V., Mandel, R. J., and Muzyczka, N. (2008). Genome-wide analysis of aging and learning-related genes in the 
hippocampal dentate gyrus. Neurobiol. Learn. Mem. 89, 379-396.

Burger, C., Nash, K., and Mandel, R. J. (2005). Recombinantadeno-associated viral vectors in the nervous system. Hum. Gene Ther. 16, 781-791.

Burke, S. N., and Barnes, C. A. (2006). Neural plasticity in the ageing brain. Nat. Rev. Neurosci. 7, 30-40.

Burke, S. N., Maurer, A. P., Yang, Z., Navratilova, Z., and Barnes, C. A. (2008). Glutamate receptor-mediated restoration of experience-dependent place field expansion plasticity in aged rats. Behav. Neurosci. 122, 535-548.

Cameron, H. A., and McKay, R. D. (1999). Restoring production of hippocampal neurons in old age. Nat. Neurosci. 2, 894-897.

Cameron, H. A., Woolley, C. S., McEwen, B. S., and Gould, E. (1993). Differentiation of newly born neurons and glia in the dentate gyrus of the adult rat. Neuroscience 56, 337-344.

Casu, M. A., Wong, T. P., De Koninck, Y., Ribeiro-da-Silva, A., and Cuello, A. C. (2002). Aging causes a preferential loss of cholinergic innervation of characterized neocortical pyramidal neurons. Cereb. Cortex 12, 329-337.

Cavallaro, S., Schreurs, B. G., Zhao, W., D'Agata, V., and Alkon, D. L. (2001). Gene expression profiles during longterm memory consolidation. Eur. J. Neurosci. 13, 1809-1815.

Chen, P.E., Errington, M. L., Kneussel, M., Chen, G., Annala, A. J., Rudhard, Y.H., Rast, G. F., Specht, C. G., Tigaret, C. M., Nassar, M. A., Morris, R. G., Bliss, T.V., and Schoepfer, R. (2009). Behavioral deficits and subregion-specific suppression of LTP in mice expressing a population of mutant NMDA receptors throughout the hippocampus. Learn Mem. 16, 635-644.

Cheng, X. R., Zhou, W. X., Zhang, Y. X., Zhou, D. S., Yang, R. F., and Chen, L. F. (2007). Differential gene expression profiles in the hippocampus of senescence-accelerated mouse. Neurobiol. Aging 28, 497-506.

Clark, A. S., Magnusson, K. R., and Cotman, C.W. (1992). In vitro autoradiography of hippocampal excitatory amino acid binding in aged Fischer 344 rats: relationship to performance on the Morris water maze. Behav. Neurosci. 106, 324-335.

Colombo, P. J., and Gallagher, M. (1998). Individual differences in spatial memory and striatal ChAT activity among young and aged rats. Neurobiol. Learn. Mem. 70, 314-327.

Colombo, P.J., Wetsel, W.C., and Gallagher, M. (1997). Spatial memory is related to hippocampal subcellular concentrations of calcium-dependent protein kinase $\mathrm{C}$ isoforms in young and aged rats. Proc. Natl. Acad. Sci. U.S.A. 94, 14195-14199.

Curcio, C. A., and Hinds, J. W. (1983). Stability of synaptic density and spine volume in dentate gyrus of aged rats. Neurobiol. Aging 4, 77-87.

D'Agata, V., and Cavallaro, S. (2003). Hippocampal gene expression profiles in passive avoidance conditioning. Eur. J. Neurosci. 18, 2835-2841.

Datson, N. A., van der Perk, J., de Kloet, E. R., and Vreugdenhil, E. (2001). Expression profile of 30,000 genes in rat hippocampus using SAGE. Hippocampus 11, 430-444.

Decker, M. W., Pelleymounter, M. A., and Gallagher, M. (1988). Effects of training on a spatial memory task on high affinity choline uptake in hippocampus and cortex in young adult and aged rats. J. Neurosci. 8, 90-99.

deToledo-Morrell, L., Geinisman, Y., and Morrell, F. (1988). Age-dependent alterations in hippocampal synaptic plasticity: relation to memory disorders. Neurobiol. Aging 9, 581-590.

Deupree, D. L., Bradley, J., and Turner, D. A. (1993). Age-related alterations in potentiation in the $\mathrm{CA} 1$ region in $\mathrm{F} 344$ rats. Neurobiol. Aging 14, 249-258.

Disterhoft, J. F., and Oh, M. M. (2007). Alterations in intrinsic neuronal excitability during normal aging. Aging Cell 6, 327-336.

Dobrossy, M.D., Drapeau, E., Aurousseau, C., Le Moal, M., Piazza, P. V., and Abrous, D. N. (2003). Differential effects of learning on neurogenesis: learning increases or decreases the number of newly born cells depending on their birth date. Mol. Psychiatry 8, 974-982.

Drapeau, E., Mayo, W., Aurousseau, C., Le Moal, M., Piazza, P. V., and Abrous, D. N. (2003). Spatial memory performances of aged rats in the water maze predict levels of hippocampal neurogenesis. Proc. Natl. Acad. Sci. U.S.A. 100, 14385-14390.

Drapeau, E., and Nora Abrous, D. (2008). Stem cell review series: role of neurogenesis in age-related memory disorders. Aging Cell 7, 569-589.

Dupret, D., Fabre, A., Dobrossy, M. D., Panatier, A., Rodriguez, J.J., Lamarque, S., Lemaire, V., Oliet, S. H., Piazza, P. V., and Abrous, D. N. (2007). Spatial learning depends on both the addition and removal of new hippocampal neurons. PLoS Biol. 5, e214. doi: 10.1371/ journal.pbio.0050214.

Dupret, D., Revest, J. M., Koehl, M., Ichas, F., De Giorgi, F., Costet, P., Abrous, D. N., and Piazza, P. V. (2008). Spatial relational memory requires hippocampal adult neurogenesis. PLoS ONE 3, e1959. doi: 10.1371/journal. pone. 0001959 .
Foster, T. C., and Kumar, A. (2007) Susceptibility to induction of longterm depression is associated with impaired memory in aged Fischer 344 rats. Neurobiol. Learn. Mem. 87, 522-535.

Freeman, W. M., Vanguilder, H. D., Bennett, C., and Sonntag, W.E. (2009). Cognitive performance and age-related changes in the hippocampal proteome. Neuroscience 159, 183-195.

Gage, F. H., and Bjorklund, A. (1986) Cholinergic septal grafts into the hippocampal formation improve spatial learning and memory in aged rats by an atropine-sensitive mechanism J. Neurosci. 6, 2837-2847.

Gage, F. H., Dunnett, S. B., and Bjorklund, A. (1984). Spatial learning and motor deficits in aged rats. Neurobiol. Aging 5, 43-48.

Gallagher, M., Burwell, R., and Burchinal, M. (1993). Severity of spatial learning impairment in aging: development of a learning index for performance in the Morris water maze. Behav. Neurosci. 107, 618-626.

Gallagher, M., and Nicolle, M. M. (1993). Animal models of normal aging: relationship between cognitive decline and markers in hippocampal circuitry. Behav. Brain Res. 57, 155-162.

Geinisman, Y. (1979). Loss of axosomatic synapses in the dentate gyrus of aged rats. Brain Res. 168, 485-492.

Geinisman, Y., de Toledo-Morrell, L. and Morrell, F. (1986). Loss of perforated synapses in the dentate gyrus: morphological substrate of memory deficit in aged rats. Proc. Natl. Acad. Sci. U.S.A. 83, 3027-3031.

Geinisman, Y., deToledo-Morrell, L., Morrell, F., Heller, R. E., Rossi, M., and Parshall, R. F. (1993). Structural synaptic correlate of long-term potentiation: formation of axospinous synapses with multiple, completely partitioned transmission zones. Hippocampus 3 , 435-445.

Geinisman, Y., Ganeshina, O., Yoshida, R., Berry, R. W., Disterhoft, J. F., and Gallagher, M. (2004). Aging, spatial learning, and total synapse number in the rat CAl stratum radiatum. Neurobiol. Aging 25, 407-416.

Geinisman, Y., Gundersen, H. J., van der Zee, E., and West, M. J. (1996). Unbiased stereological estimation of the total number of synapses in a brain region. J. Neurocytol. 25, 805-819.

Gould, E., Beylin, A., Tanapat, P., Reeves, A., and Shors, T. J. (1999). Learning enhances adult neurogenesis in the hippocampal formation. Nat. Neurosci. 2, 260-265.

Gozal, E., Gozal, D., Pierce, W. M. Thongboonkerd, V., Scherzer, J. A.
Sachleben, L. R., Jr., Brittian, K. R., Guo, S. Z., Cai, J., and Klein, J. B. (2002). Proteomic analysis of CA1 and CA3 regions of rat hippocampus and differential susceptibility to intermittent hypoxia. J. Neurochem. 83, 331-345.

Greene, J. G., Borges, K., and Dingledine, R. (2009). Quantitative transcriptional neuroanatomy of therathippocampus: evidence for wide-ranging, pathwayspecific heterogeneity among three principal cell layers. Hippocampus 19, 253-264.

Grover, L. M., and Teyler, T. J. (1990). Two components of long-term potentiation induced by different patterns of afferent activation. Nature 347, 477-479.

Haberman, R. P., Colantuoni, C., Stocker, A. M., Schmidt, A. C., Pedersen, J. T., and Gallagher, M. (2009). Prominent hippocampal CA3 gene expression profile in neurocognitive aging. Neurobiol. Aging doi: 10.1016/j. neurobiolaging.2009.10.005. [Epub ahead of print].

Haberman, R. P., Lee, H. J., Colantuoni, C., Koh, M. T., and Gallagher, M. (2008). Rapid encoding of new information alters the profile of plasticity-related mRNA transcripts in the hippocampal CA3 region. Proc. Natl. Acad. Sci. U.S.A. 105, 10601-10606.

Hanks, S. D., and Flood, D. G. (1991). Region-specific stability of dendritic extent in normal human aging and regression in Alzheimer's disease. I. CA1 of hippocampus. Brain Res. 540, 63-82.

Hastings, N. B., and Gould, E. (1999). Rapid extension of axons into the CA3 region by adult-generated granule cells. J. Comp. Neurol. 413, 146-154.

Havekes, R., and Abel, T. (2009). Genetic dissection of neural circuits and behavior in Mus musculus. Adv. Genet. 65, 1-38.

Heine, V. M., Maslam, S., Joels, M., and Lucassen, P. J. (2004). Prominent decline of newborn cell proliferation, differentiation, and apoptosis in the aging dentate gyrus, in absence of an age-related hypothalamus-pituitaryadrenal axis activation. Neurobiol. Aging 25, 361-375.

Hemby, S. E., Trojanowski, J. Q., and Ginsberg, S. D. (2003). Neuronspecific age-related decreases in dopamine receptor subtype mRNAs. J. Comp. Neurol. 456, 176-183.

Jackson, T. C., Rani, A., Kumar, A., and Foster, T. C. (2009). Regional hippocampal differences in AKT survival signaling across the lifespan: implications for CA1 vulnerability with aging. Cell Death Differ. 16, 439-448.

Jerusalinsky, D., and Epstein, A. L. (2006). Amplicon vectors as outstanding tools 
to study and modify cognitive functions. Curr. Gene Ther. 6, 351-360.

Kadish, I., Thibault, O., Blalock, E. M., Chen, K. C., Gant, J. C., Porter, N. M., and Landfield, P. W. (2009). Hippocampal and cognitive aging across the lifespan: a bioenergetic shift precedes and increased cholesterol trafficking parallels memory impairment. J. Neurosci. 29, 1805-1816.

Kempermann, G., and Gage, F. H. (2002). Genetic determinants of adult hippocampal neurogenesis correlate with acquisition, but not probe trial performance, in the water maze task. Eur. J. Neurosci. 16, 129-136.

Kempermann, G., Kuhn, H. G., and Gage, F. H. (1998). Experience-induced neurogenesis in the senescent dentate gyrus. J. Neurosci. 18, 3206-3212.

Kuhn, H. G., Dickinson-Anson, H., and Gage, F. H. (1996). Neurogenesis in the dentate gyrus of the adult rat: age-related decrease of neuronal progenitor proliferation. J. Neurosci. 16, 2027-2033.

Kumar, A., Bodhinathan, K., and Foster, T. C. (2009). Susceptibility to calcium dysregulation during brain aging. Front. Ag. Neurosci. 1:2. doi: 10.3389/ neuro.24.002.2009.

Lanahan, A., Lyford, G., Stevenson, G. S., Worley, P. F., and Barnes, C. A. (1997). Selective alteration of long-term potentiation-induced transcriptional response in hippocampus of aged, memory-impaired rats. J. Neurosci. 17, 2876-2885.

Lee, H. K., Min, S. S., Gallagher, M., and Kirkwood,A. (2005). NMDA receptorindependent long-term depression correlates with successful aging in rats. Nat. Neurosci. 8, 1657-1659.

Lee, Y. S., and Silva, A. J. (2009). The molecular and cellular biology of enhanced cognition. Nat. Rev. Neurosci. 10, 126-140.

Leil, T. A., Ossadtchi, A., Nichols, T. E., Leahy, R. M., and Smith, D. J. (2003). Genes regulated by learning in the hippocampus. J. Neurosci. Res. 71, 763-768.

Lein, E. S., Zhao, X., and Gage, F. H. (2004). Defining a molecular atlas of the hippocampus using DNA microarrays and high-throughput in situ hybridization. J. Neurosci. 24, 3879-3889.

Le Jeune, H., Cecyre, D., Rowe, W., Meaney, M. J., and Quirion, R. (1996). Ionotropic glutamate receptor subtypes in the aged memory-impaired and unimpaired Long-Evans rat. Neuroscience 74, 349-363.

Lemaire, V., Koehl, M., Le Moal, M., and Abrous, D. N. (2000). Prenatal stress produces learning deficits associated with an inhibition of neurogenesis in the hippocampus. Proc. Natl. Acad. Sci. U.S.A. 97, 11032-11037.

Leuner, B., Glasper, E. R., and Gould, E. (2009). Thymidine analog methods for studies of adult neurogenesis are not equally sensitive. J. Comp. Neurol. 517, 123-133.

Leuner, B., Gould, E., and Shors, T. J. (2006). Is there a link between adult neurogenesis and learning? Hippocampus 16, 216-224.

Lichtenwalner, R. J., Forbes, M. E., Bennett, S. A., Lynch, C. D., Sonntag, W. E., and Riddle, D. R. (2001). Intracerebroventricular infusion of insulin-like growth factor-I ameliorates the age-related decline in hippocampal neurogenesis. Neuroscience 107, 603-613.

Lindner, M. D., Balch, A. H., and VanderMaelen, C. P. (1992). Short forms of the "reference-" and "working-memory" Morris water maze for assessing age-related deficits. Behav. Neural Biol. 58, 94-102.

Lister, J. P., and Barnes, C. A. (2009). Neurobiological changes in the hippocampus during normative aging. Arch. Neurol. 66, 829-833.

Lukiw, W. J. (2004). Gene expression profiling in fetal, aged, and Alzheimer hippocampus: a continuum of stressrelated signaling. Neurochem. Res. 29, 1287-1297.

Lundberg, C., Bjorklund, T., Carlsson, T., Jakobsson, J., Hantraye, P., Deglon, N., and Kirik, D. (2008). Applications of lentiviral vectors for biology and gene therapy of neurological disorders. Curr. Gene Ther. 8, 461-473.

Luo, Y., Long, J. M., Spangler, E. L., Longo, D. L., Ingram, D. K., and Weng, N. P. (2001). Identification of maze learning-associated genes in rat hippocampus by cDNA microarray. $J$. Mol. Neurosci. 17, 397-404.

Madsen, T. M., Kristjansen, P.E., Bolwig, T. G., and Wortwein, G. (2003). Arrested neuronal proliferation and impaired hippocampal function following fractionated brain irradiation in the adult rat. Neuroscience 119, 635-642.

Markham, J. A., McKian, K. P., Stroup, T. S., and Juraska, J. M. (2005). Sexually dimorphic aging of dendritic morphology in CA1 of hippocampus. Hippocampus 15, 97-103.

Markowska, A. L., Stone, W. S., Ingram, D. K., Reynolds, J., Gold, P. E., Conti, L. H., Pontecorvo, M. J., Wenk, G. L., and Olton, D. S. (1989). Individual differences in aging: behavioral and neurobiological correlates. Neurobiol. Aging 10, 31-43.

Mayhew, T. M., and Gundersen, H. J. (1996). 'If you assume, you can make an ass out of $u$ and me': a decade of the disector for stereological counting of particles in 3D space. J. Anat. 188 (Pt 1), 1-15.

McDonald, H. Y., and Woitowicz, J. M. (2005). Dynamics of neurogenesis in the dentate gyrus of adult rats. Neurosci. Lett. 385, 70-75.

Merrill, D. A., Karim, R., Darraq, M., Chiba, A. A., and Tuszynski, M. H. (2003). Hippocampal cell genesis does not correlate with spatial learning ability in aged rats. J. Comp. Neurol. 459, 201-207.

Moore, C. I., Browning, M. D., and Rose, G. M. (1993). Hippocampal plasticity induced by primed burst, but not long-term potentiation, stimulation is impaired in area CA1 of aged Fischer 344 rats. Hippocampus 3, 57-66.

Morgenstern, N. A., Lombardi, G., and Schinder, A. F. (2008). Newborn granule cells in the ageing dentate gyrus. $J$. Physiol. 586, 3751-3757.

Morris, R. (1984). Developments of a water-maze procedure for studying spatial learning in the rat. J. Neurosci. Methods 11, 47-60.

Nicholson, D. A., Yoshida, R., Berry, R. W., Gallagher, M., and Geinisman, Y. (2004). Reduction in size of perforated postsynaptic densities in hippocampal axospinous synapses and age-related spatial learning impairments. $J$. Neurosci. 24, 7648-7653.

Nicolle, M. M., Gallagher, M., and McKinney, M. (2001). Visualization of muscarinic receptor-mediated phosphoinositide turnover in the hippocampus of young and aged, learning-impaired Long Evans rats. Hippocampus 11, 741-746.

Norris, C. M., Korol, D. L., and Foster T. C. (1996). Increased susceptibility to induction of long-term depression and long-term potentiation reversal during aging. J. Neurosci. 16 , 5382-5392.

Oh, M. M., Oliveira, F. A., and Disterhoft, J.F. (2010). Learning and aging related changes in intrinsic neuronal excitability. Front. Ag. Neurosci. 2:2. doi 10.3389/neuro.24.002.2010.

Olariu, A., Cleaver, K. M., and Cameron, H. A. (2007). Decreased neurogenesis in aged rats results from loss of granule cell precursors without lengthening of the cell cycle. J. Comp. Neurol. 501, 659-667.

Oler, J. A., and Markus, E. J. (2000). Agerelated deficits in the ability to encode contextual change: a place cell analysis. Hippocampus 10, 338-350.

Pawlowski, T. L., Bellush, L. L., Wright, A. W., Walker, J. P., Colvin, R. A., and Huentelman, M. J. (2009). Hippocampal gene expression changes during age-related cognitive decline. Brain Res. 1256, 101-110.
Poe, B. H., Linville, C., Riddle, D. R., Sonntag, W.E., and Brunso-Bechtold, J. K. (2001).Effects of age and insulin-like growth factor- 1 on neuron and synapse numbers in area $\mathrm{CA} 3$ of hippocampus. Neuroscience 107, 231-238.

Raber, J., Rola, R., LeFevour, A., Morhardt, D., Curley, J., Mizumatsu, S., VandenBerg, S. R., and Fike, J. R. (2004). Radiation-induced cognitive impairments are associated with changes in indicators of hippocampal neurogenesis. Radiat. Res. 162, 39-47.

Rao, M. S., Hattiangady, B., AbdelRahman, A., Stanley, D. P., and Shetty, A. K. (2005). Newly born cells in the ageing dentate gyrus display normal migration, survival and neuronal fate choice but endure retarded early maturation. Eur. J. Neurosci. 21, 464-476.

Rapp, P. R., Rosenberg, R. A., and Gallagher,M. (1987). An evaluation of spatial information processing in aged rats. Behav. Neurosci. 101, 3-12.

Rapp, P. R., Stack, E. C., and Gallagher, M. (1999). Morphometric studies of the aged hippocampus: I. Volumetric analysis in behaviorally characterized rats. J. Comp. Neurol. 403, 459-470.

Rasmussen, T., Schliemann, T., Sorensen, J. C., Zimmer, J., and West, M. J. (1996). Memory impaired aged rats: no loss of principal hippocampal and subicular neurons. Neurobiol. Aging 17, 143-147.

Richter,J.D., and Klann, E. (2009). Making synaptic plasticity and memory last: mechanisms of translational regulation. Genes Dev. 23, 1-11.

Robles, Y., Vivas, M., a, P. E., OrtizZuazaga, H. G., Felix, J., Ramos, X., and Pena de Ortiz,S. (2003). Hippocampal gene expression profiling in spatial discrimination learning. Neurobiol. Learn. Mem. 80, 80-95.

Rogalski, E. J., Murphy, C. M., deToledoMorrell, L., Shah, R. C., Moseley, M. E., Bammer, R., and Stebbins, G. T. (2009). Changes in parahippocampal white matter integrity in amnestic mild cognitive impairment: a diffusion tensor imaging study. Behav. Neurol. 21, 51-61.

Rosenzweig, E. S., and Barnes, C.A. (2003). Impact of aging on hippocampal function: plasticity, network dynamics, and cognition. Prog. Neurobiol. 69, 143-179.

Rowe, W. B., Blalock, E. M., Chen, K. C., Kadish, I., Wang, D., Barrett, J. E., Thibault, O., Porter, N. M., Rose, G. M., and Landfield, P. W. (2007). Hippocampal expression analyses reveal selective association of immediate-early, neuroenergetic, and myelinogenic pathways with cognitive impairment in aged rats. J. Neurosci. 27, 3098-3110. 
Sava, S., and Markus, E. J. (2008). Activation of the medial septum reverses age-related hippocampal encoding deficits: a place field analysis. J. Neurosci. 28, 1841-1853.

Schubert, M., Breakefield, X., Federoff, H., Frederickson, R. M., and Lowenstein, P. R. (2008). Gene delivery to the nervous system. Mol. Ther. 16, 640-646.

Schulz, D., Huston, J. P., Jezek, K., Haas, H. L., Roth-Harer, A., Selbach, O., and Luhmann, H. J. (2002). Water maze performance, exploratory activity, inhibitory avoidance and hippocampal plasticity in aged superior and inferior learners. Eur. J. Neurosci. 16, 2175-2185.

Schurmans, S., Schiffmann, S. N., Gurden, H.,Lemaire, M.,Lipp, H.P., Schwam, V., Pochet, R., Imperato, A., Bohme, G. A., and Parmentier, M. (1997). Impaired long-term potentiation induction in dentate gyrus of calretinin-deficient mice. Proc. Natl. Acad. Sci. U.S.A. 94, 10415-10420.

Seki, T., and Arai, Y. (1995). Age-related production of new granule cells in the adult dentate gyrus. Neuroreport 6, 2479-2482.

Seri, B., Garcia-Verdugo, J. M., ColladoMorente, L., McEwen, B. S., and Alvarez-Buylla, A. (2004). Cell types, lineage, and architecture of the germinal zone in the adult dentate gyrus. $J$. Comp. Neurol. 478, 359-378.

Shen, J., Barnes, C. A., McNaughton, B. L., Skaggs, W. E., and Weaver, K. L. (1997). The effect of aging on experience-dependent plasticity of hippocampal place cells. J. Neurosci. 17, 6769-6782.

Shors, T. J., Miesegaes, G., Beylin, A., Zhao, M., Rydel, T., and Gould, E. (2001). Neurogenesis in the adult is involved in the formation of trace memories. Nature 410, 372-376.

Shors, T. J., Townsend, D. A., Zhao, M., Kozorovitskiy, Y., and Gould, E. (2002). Neurogenesis may relate to some but not all types of hippocampal-dependent learning. Hippocampus 12, 578-584.

Smith, T. D., Adams, M. M., Gallagher, M., Morrison, J. H., and Rapp, P. R. (2000). Circuit-specific alterations in hippocampal synaptophysin immunoreactivity predict spatial learning impairment in aged rats. J. Neurosci. 20, 6587-6593

Snyder, J. S., Choe, J. S., Clifford, M. A., Jeurling, S. I., Hurley, P., Brown, A., Kamhi, J. F., and Cameron, H. A. (2009a). Adult-born hippocampal neurons are more numerous, faster maturing, and more involved in behavior in rats than in mice. $J$. Neurosci. 29, 14484-14495.
Snyder, J. S., Radik, R., Wojtowicz, J. M., and Cameron, H. A. (2009b). Anatomical gradients of adult neurogenesis and activity: young neurons in the ventral dentate gyrus are activated by water maze training. Hippocampus 19, 360-370

Snyder, J. S., Ramchand, P., Rabbett, S., Radik, R., Wojtowicz, J. M., and Cameron, H. A. (2009c). Septotemporal gradients of neurogenesis and activity in 13-month-old rats. Neurobiol. Aging doi: 10.1016/j. neurobiolaging.2009.05.022. [Epub ahead of print].

Snyder, J. S., Hong, N. S., McDonald, R. J., and Wojtowicz, J. M. (2005). A role for adult neurogenesis in spatial long-term memory. Neuroscience 130, 843-852.

Southgate, T., Kroeger, K. M., Liu, C., Lowenstein, P. R., and Castro, M. G. (2008). Gene transfer into neural cells in vitro using adenoviral vectors. Curr. Protoc. Neurosci. (Chapter 4, Unit 4 23).

Stephan, A., Davis, S., Salin, H., Dumas, S., Mallet, J., and Laroche, S. (2002). Age-dependent differential regulation of genes encoding APP and alphasynuclein in hippocampal synaptic plasticity. Hippocampus 12, 55-62.

Stranahan, A. M., Lee, K., Becker, K. G., Zhang, Y., Maudsley, S., Martin, B., Cutler, R. G., and Mattson, M. P. (2008). Hippocampal gene expression patterns underlying the enhancement of memory by running in aged mice. Neurobiol. Aging 31, 1937-1949.

Swanson, L. W., Kohler, C., and Bjorklund, A. (1987)."Thelimbic region.I: the septohippocampal system," in Handbook in Chemical Neuroanatomy, Vol. 5, Part I, eds A. Bjorklund, T. Hokfelt, and L. W. Swanson (Amsterdam: Elsevier), 125-227.

Tanila,H., Shapiro, M., Gallagher, M., and Eichenbaum, H. (1997). Brain aging: changes in the nature of information coding by the hippocampus. $J$. Neurosci. 17, 5155-5166.

Thibault, O., Gant, J. C., and Landfield P. W. (2007). Expansion of the calcium hypothesis of brain aging and Alzheimer's disease: minding the store. Aging Cell 6, 307-317.

Thibault, O., and Landfield, P. W. (1996) Increase in single L-type calcium channels in hippocampal neurons during aging. Science 272, 1017-1020.

Tombaugh, G. C., Rowe, W. B., Chow, A. R., Michael, T. H., and Rose, G. M. (2002). Theta-frequency synaptic potentiation in CA1 in vitro distinguishes cognitively impaired from unimpaired aged Fischer 344 rats. J. Neurosci. 22, 9932-9940.
Toni, N., Buchs, P. A., Nikonenko, I. Bron, C. R., and Muller, D. (1999). LTP promotes formation of multiple spine synapses between a single axon terminal and a dendrite. Nature 402 421-425.

Torres-Munoz, J. E., Van Waveren, C. Keegan, M. G., Bookman, R. J., and Petito, C. K. (2004). Gene expression profiles in microdissected neurons from human hippocampal subregions. Brain Res. Mol. Brain Res. 127, 105-114.

Uemura, E. (1985). Age-related changes in the subiculum of Macaca mulatta: dendritic branching pattern. Exp. Neurol. 87, 412-427.

Van der Borght, K., Wallinga, A. E., Luiten, P. G., Eggen, B. J., and Van der Zee, E. A. (2005). Morris water maze learning in two rat strains increases the expression of the polysialylated form of the neural cell adhesion molecule in the dentate gyrus but has no effect on hippocampal neurogenesis. Behav. Neurosci. 119, 926-932.

van der Staay, F. J., and de Jonge, M. (1993). Effects of age on water escape behavior and on repeated acquisition in rats. Behav. Neural Biol. 60, 33-41. van Praag, H., Schinder, A. F., Christie, B R., Toni, N., Palmer, T. D., and Gage, F. H. (2002). Functional neurogenesis in the adult hippocampus. Nature 415 1030-1034.

van Praag, H., Shubert, T., Zhao, C., and Gage, F. H. (2005). Exercise enhances learning and hippocampal neurogenesis in aged mice. J. Neurosci. 25 8680-8685.

Verbitsky, M., Yonan, A. L., Malleret, G., Kandel, E. R., Gilliam, T. C., and Pavlidis, P. (2004). Altered hippocampal transcript profile accompanies an age-related spatial memory deficit in mice. Learn. Mem. 11, 253-260.

Walter, J., Keiner, S., Witte, O. W., and Redecker, C. (2009). Age-related effects on hippocampal precursor cell subpopulations and neurogenesis. Neurobiol. Aging doi: 10.1016/j. neurobiolaging.2009.11.011. [Epub ahead of print].

Wei, X., Zhang, Y., and Zhou, J. (1999). Differential display and cloning of the hippocampal gene mRNAs in senescence accelerated mouse. Neurosci. Lett. 275, 17-20.

West, M. J., Kawas, C. H., Stewart, W F., Rudow, G. L., and Troncoso, J. C. (2004). Hippocampal neurons in preclinical Alzheimer's disease. Neurobiol. Aging 25, 1205-1212.

West, M. J., Slomianka, L., and Gundersen, H. J. (1991). Unbiased stereological estimation of the total number of neurons in the subdivisions of the rat hippocampus using the optical fractionator. Anat. Rec. 231, 482-497.

Wilson, I.A., Gallagher, M., Eichenbaum, H., and Tanila, H. (2006). Neurocognitive aging: prior memories hinder new hippocampal encoding. Trends Neurosci. 29, 662-670.

Wilson, I. A., Ikonen, S., Gallagher, M., Eichenbaum, H., and Tanila, H. (2005). Age-associated alterations of hippocampal place cells are subregion specific. J. Neurosci. 25, 6877-6886.

Wilson, I. A., Ikonen, S., McMahan, R. W., Gallagher, M., Eichenbaum, H., and Tanila, H. (2003). Place cell rigidity correlates with impaired spatial learning in aged rats. Neurobiol. Aging 24, 297-305.

Witter, M. P., and Amaral, D. G. (2004) "Hippocampal formation," in The Rat Nervous System, ed. G. Paxinos (San Diego: Elsevier), 635-704.

Wu, W., Brickman, A. M., Luchsinger, J., Ferrazzano, P., Pichiule, P., Yoshita, M. Brown, T., DeCarli, C., Barnes, C. A., Mayeux, R., Vannucci, S. J., and Small, S. A. (2008). The brain in the age of old: the hippocampal formation is targeted differentially by diseases of late life. Ann. Neurol. 64, 698-706.

Zarow, C., Vinters, H. V., Ellis, W. G., Weiner, M. W., Mungas, D., White, L., and Chui, H. C. (2005). Correlates of hippocampal neuron number in Alzheimer's disease and ischemic vascular dementia. Ann. Neurol. 57, 896-903.

Zhao, X., Lein, E. S., He, A., Smith, S. C., Aston, C., and Gage, F. H. (2001). Transcriptional profiling reveals strict boundaries between hippocampal subregions. J. Comp. Neurol. 441, 187-196.

Conflict of Interest Statement: The author declares that the research was conducted in the absence of any commercial or financial relationships that could be construed as a potential conflict of interest.

Received: 07 January 2010; paper pending published: 15 February 2010; accepted: 17 August 2010; published online: 14 October 2010

Citation: Burger C (2010) Region-specific genetic alterations in the aging hippocampus: implications for cognitive aging. Front. Ag. Neurosci. 2:140. doi: 10.3389/ fnagi.2010.00140

Copyright $($ C 2010 Burger. This is an openaccess article subject to an exclusive license agreement between the authors and the Frontiers Research Foundation, which permits unrestricted use, distribution, and reproduction in any medium, provided the original authors and source are credited. 